fettered. If a man sets himself to improve an existing process, he very likely may succeed, but he will not effect a revolution in manufacture. The purely scientific investigator who is free to follow indications of no apparent commercial import has not infrequently made discoveries of a radical nature, which have entirely changed some particular industry. I do not recommend the one to the exclusion of the other; both are best; and both are best attained by an intimate association between the universities and the chemical works. The investigator often learns much by the study of industrial processes. The chemical manufacturer who is keenly alive to his own interests will not fail to keep himself in touch with every discovery, however little it appears to be connected with his own industry.

\section{THE GRAIN IN PHOTOGRAPHIC FILMS}

I $\mathrm{N}$ the September number of the Astrophysical Journal I Mr. R. J. Wallace gives an account of his investigation of the circumstances that control the size of the silver particles in a developed gelatino-bromide plate. Of four rapid plates of American make, the "Seed 27, Gilt Edge" was found to give the best results. It was the most uniform in speed from time to time, and gave the least amount of "chemical fog," the smallest particles of silver, and the most regular distribution of them. While the particles were found to be, generally speaking, spherical in ordinary plates, isochromatic plates of several makes showed the peculiarity of having almost exclusively elongated (the author calls them "spicular") grains at the surface of the film, while in passing downwards through the film they gradually gave place to rounded particles, until close to the supporting glass these latter were the only ones found. Intensification increases the size of the particles; this is the common experience of those interested in these matters,

formation of "group-particles" because they dissolved off the film after development and examined a new film made from the product.

\title{
THE DUCHESS OF SUTHERLAND'S SCHOOL AT GOLSPIE.
}

$\mathrm{A}_{\mathrm{S}}$ announced in our columns last year (September 24, 1903), the formal foundation of the Duchess of Sutherland's Technical School at Golspie was inaugurated on September 8, 1903, by Lord Balfour of Burleigh, at that time Secretary for Scotland. The building is, we are informed, now completed, the total cost of erection and equipment having exceeded $16,000 l$, exclusive of the site and grounds given by the Duke of Sutherland. The school is a handsome structure in white freestone, and three storeys in height. It contains altogether fifty-six rooms, including fourteen class-rooms, workshops, laboratories, museum, \&c. The dormitories are 50 feet by $2 \mathrm{I}$ feet, with bathrooms and lavatories attached. The school when full can receive sixty pupils. The curriculum covers a period of three years, and the subjects comprised are such as are most likely to meet local industrial requirements, the whole course being framed on a sound scientific basis. In drafting the original scheme the duchess had the cooperation of Prof. R. Meldola, Prof. Magnus Maclean, Lord Balfour of Burleigh, the Right Hon. R. B. Haldane, and Mr. Struthers, of the Scotch Education Department. A formal deed has been executed by the duchess ensuring the perpetuity of the school, and appointing for its management a local board of governors, the duchess herself being chairman and the duke a member of this board. An advisory committee has also been appointed consisting of leading educationists and representatives of Highland societies, as well as Her Grace's original advisers.

The building and equipment fund has been raised entirely by private voluntary subscriptions, the

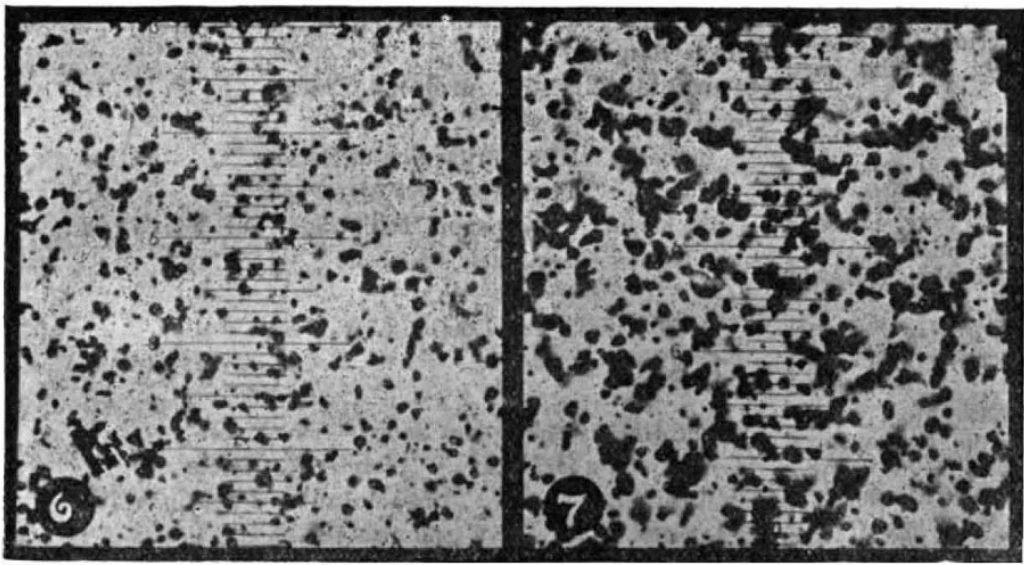

Before Intensification ( $\mathrm{r}^{*} 3$ to $4^{\circ} \mathrm{o} \mu$ )

FIG. x. - Photomicrographs of Silver " Grain." Duke of Sutherland having contributed $8000 l$. Other munificent supporters of the scheme are Mr. Andrew Carnegie and Lord Strathcona, the Dukes of Portland and Westminster, Mr. James Coats, of Paisley, and Mrs. Carnegie. The cordial support which this new educational departure has received in Scotland will be recognised when it is stated that out of the sixty places in the school forty are provided for by bursaries guaranteed by various benefactors interested in the counties of Sutherland, Caithness, Ross and Cromarty, and one (by Mr. Dewar) for a student from Inverness-shire. Another indication of the local practical interest in the scheme is that at the opening of the school for regular work on October 3 the claims of more than sixty applicants for admission had been considered by the board of governors. Out of these, twenty-five bursars have been admitted as the first batch, and further admissions of bursars wili

but the author's demonstration is of special interest, as he performed the intensification with a brush, using the mercury and ammonia method, without shifting the plate, so that he was able to photograph the identical particles before and after the operation. The same grains can easily be traced in the two photographs reproduced. The magnification is 430 diameters. The author also shows the difference between rapid and slow development. In the first case he considers that the silver particles most nearly approach the size of the original particles of silver salt from which they are produced, while by prolonged development they become enlarged by reason of the formation of "groupparticles " as well as by accretion. For the finest grain the author deprecates slow development. In a postscript reference is made to the deduction of Messrs. Lumière and Seyewetz from their recent experiments to the effect that neither the temperature, concentration, nor duration of development practically affects the size of the grain. The author considers that these investigators have neglected the be sanctioned for next year and for 1906 .

It is proposed to work the school as a higher grade school under the Scotch Board of Education, and, in addition to the scientific and technical subjects, the ordinary literary and humanitarian subjects will be carried on from the elementary school stage, the standard of qualification required for admission as a bursar being that he should have completed his thirteenth year and have received the "merit certificate" or its equivalent. It is of interest to learn that the elementary schools from which the technical school will be supplied with pupils are cooperating most sympathetically in carrying out the scheme. One of the difficulties, as we learn from Prof. Meldola, which has beset the school in Essex founded by Lady Warwick, sister of the Duchess of Sutherland, has hitherto been the want of cooperation on the part of the local elementary schoolmasters. The head-master of the new school is Mr. E. W. Read, of Cambridge, formerly agricultural instructor at the Northeastern County School, Barnard Castle, Durham.

$$
\text { No. } 1823 \text {, vOL. } 70]
$$

